\title{
Contribuição do ácido giberélico no tamanho de frutos do tomateiro
}

\author{
Ricardo Antonio Ayub* \\ Bráulio Luciano Alves Rezende \\ Departamento de Fitotecnia e Fitossanidade \\ Universidade Estadual de Ponta Grossa \\ CEP 84030-900, Ponta Grossa-PR, Brasil \\ *Autor para correspondência \\ rayub@uepg.br
}

Submetido em 07/04/2010

Aceito para publicação em 24/09/2010

\section{Resumo}

Com o objetivo de avaliar o comportamento de frutos de tomateiro submetidos a concentrações crescentes de ácido giberélico $\left(\mathrm{GA}_{3}\right)$, implantou-se um ensaio no município de Irati-PR, em uma área comercial de tomate cv. Fanny, em setembro e conduzido em sistema de cerca cruzada com uma haste por planta. Os tratamentos utilizados foram: 0, 30, 60, 90 e 120ppm de $\mathrm{GA}_{3}$, aplicados quando o diâmetro dos primeiros frutos do segundo cacho atingiu aproximadamente $10 \mathrm{~mm}$. Na colheita, quando os frutos apresentavam $30 \%$ a $50 \%$ de cor vermelha, foram avaliados a massa fresca, comprimento, diâmetros longitudinal e transversal do fruto. A aplicação de $120 \mathrm{ppm}$ de $\mathrm{GA}_{3}$ proporcionou máxima massa fresca e dimensões de frutos de tomate cv. Fanny.

Unitermos: ácido giberélico, Lycopersicon esculentum Mill., produção

\section{Abstract}

Gibberellic acid contribution to tomato fruit size. With the aim of assessing the behavior of tomato fruits subjected to increasing concentrations of gibberellic acid $\left(\mathrm{GA}_{3}\right)$, research was carried out in the municipality of Irati, Paraná State, Brazil, within a commercial area of tomato crops, cultivar Fanny, in September under the crossing fence system with a single branch per plant. The adopted treatments were as follows: $0,30,60,90$, and 120ppm of $\mathrm{GA}_{3}$, applied whenever the diameter of the first fruits of the second clusters reached roughly 10 $\mathrm{mm}$. At harvest when the fruits had achieved 30 to $50 \%$ of reddish color, the fresh mass, length, and longitudinal and transversal diameters were measured. The application of $120 \mathrm{ppm}$ of $\mathrm{GA}_{3}$ provided maximum fresh mass and dimensions.

Key words: crop production, gibberellic acid, Lycopersicon esculentum Mill.

\section{Introdução}

O tomateiro (Lycopersicon esculentum Mill., Solanaceae) é originário da costa andina e se difundiu por todo mundo, ocupando lugar de destaque entre as olerícolas
(Fontes e Silva, 2002). É uma importante hortaliça, não só em termos de produção como também em valor econômico, por ser amplamente consumida e industrializada (Lima et al., 2005). É a segunda hortaliça mais cultivada no mundo, perdendo apenas para a batata. No Brasil, a 
tomaticultura ocupa um lugar de destaque, tendo uma das maiores produtividades mundiais alcançando, em média 60 toneladas por hectare (Cançado Jr. et al., 2003).

Dentre as inúmeras cultivares existentes no mercado, a cultivar Fanny pode ser considerada uma excelente opção, devido aos genes de resistência como V (Verticilium), F1 (Fusarium raça 1), F2 (Fusaruim raça 2), N (nematóides Meloidogyne incognita e M. javanica) e TMV (Vírus do Mosaico do Fumo), além de ser altamente produtiva, de hábito de crescimento indeterminado e pertencente ao grupo saladinha (Fontes e Silva, 2002).

$\mathrm{Na}$ comercialização de frutos para o mercado in natura, o interesse é a produção de frutos de maior tamanho, pois são os que atingem maiores preços no mercado. Na prática, para que se possibilite o aumento do tamanho de frutos, os produtores recorrem a tratos culturais como a poda de haste e raleio de frutos da inflorescência, popularmente conhecido como cacho (Man et al., 2003). No entanto, para a realização de tais tratos culturais é necessária uma maior demanda de mão-deobra especializada, o que aumenta o custo de produção.

Contudo, a utilização de fitorreguladores para um aumento de produtividade e de qualidade de frutos tem sido estudada, sendo as giberelinas os fitorreguladores mais empregados e o $\mathrm{GA}_{3}$ o seu melhor representante (Bunger-Kibler e Bangerth, 1982; Sawhney, 1984). Esse regulador de crescimento atua na divisão e o alongamento celular, principalmente em células jovens (Kerbauy, 2004). Em tomate, o uso deste fitohormônio depende do balanço hormonal endógeno (Castillo et al., 2005) e é influenciado pelo momento de aplicação, tipo e dose do hormônio empregado, cultivar, estado nutricional das plantas e interação com o ambiente (Stover et al., 2000). O efeito desse fitorregulador foi observado em estudos com frutos de tomate partenocárpicos, onde a aplicação de $\mathrm{GA}_{3}$ e ácido diclorofenóxiacético $(2,4-\mathrm{D})$ na fase inicial de desenvolvimento dos frutos preveniu a senescência e induziu o rápido crescimento dos frutos em relação à autopolinização (Aguero et al., 1996).

Assim, levando em consideração o fato de que uma produção rentável está baseada na quantidade e qualidade de fruto colhido, o presente trabalho objetivou avaliar o comportamento de frutos de tomateiro quando submetido a doses crescentes de ácido giberélico.

\section{Material e Métodos}

O experimento foi realizado em uma área de produção comercial de tomate para mesa localizada no município de Irati, PR, na qual foi utilizada a cultivar Fanny tutorada no sistema de cerca cruzada em campo aberto. A cultura foi implantada através do transplante de mudas em 15 de setembro de 2006, tendo a planta conduzida com uma haste e sem o raleio dos frutos. Os demais tratos culturais (tutoramento, desbrota, retirada do ápice, capinas, adubação e outras) foram conduzidos de acordo com as recomendações para a cultura tutorada.

O delineamento experimental utilizado foi inteiramente ao acaso com cinco tratamentos e cinco repetições. Cada repetição foi composta de cinco plantas onde se aproveitou dois frutos por cacho, totalizando 10 frutos por repetição.

Os tratamentos constaram de cinco concentrações de $\mathrm{AG}_{3}(0 ; 30 ; 60 ; 90$ e $120 \mathrm{ppm})$, sendo aplicados quando os primeiros frutos do segundo cacho estavam com aproximadamente $10 \mathrm{~mm}$ de diâmetro e com os últimos botões florais abertos. A aplicação foi realizada por pulverização dirigida apenas ao segundo cacho.

Aos noventa dias após o transplante foram colhidos os dois primeiros frutos de cada cacho quando apresentavam de 30 a $50 \%$ de cor vermelha. Os frutos de tomate foram submetidos a avaliações de comprimento, diâmetro longitudinal e transversal, com o auxilio de um paquímetro, e massa dos frutos, determinada com o uso de uma balança digital de precisão.

Os dados foram submetidos à análise de regressão polinomial com o auxilio do programa ESTAT.

\section{Resultados e Discussão}

Conforme se observa na Figura 1, a massa do fruto aumentou linearmente com o aumento da concentração de ácido giberélico aplicado, superando em $20 \mathrm{~g}$ o peso da testemunha quando aplicado acima de 60ppm. Contrariamente, Martins e Castro (1997) verificaram que aplicação de $50 \mathrm{ppm} \mathrm{GA}_{3}$ no fruto do tomateiro não resultou em ganho de peso. Além disso, os autores relatam que houve maturação precoce da placenta em 
relação ao pericarpo e a presença de frutos geminados. Com a aplicação de 120ppm de $\mathrm{GA}_{3}$ proporcionou maior massa fresca de frutos $(214,17 \mathrm{~g})$, próximo à descrita pela empresa para o fruto $(230 \mathrm{~g})$.

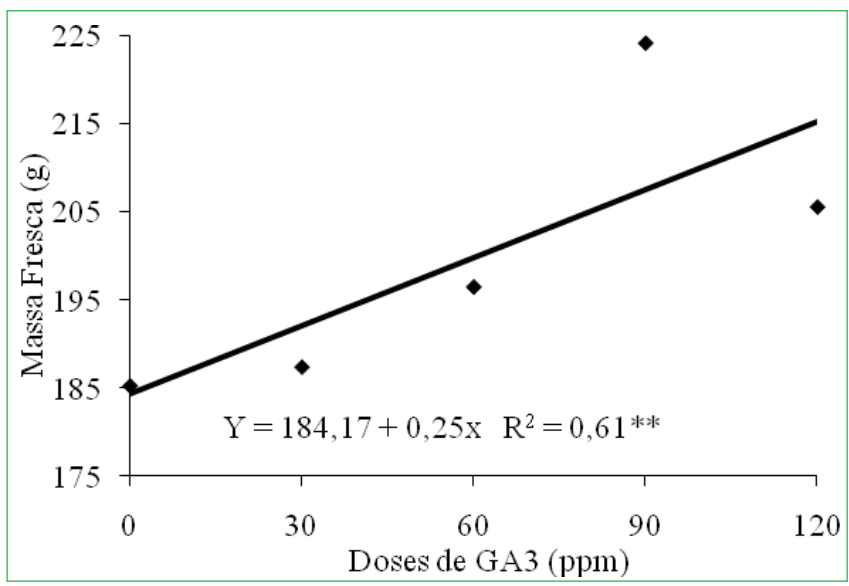

FIGURA 1: Massa fresca de frutos de tomate (Lycopersicon esculentum Mill., Solanaceae) cv. Fanny pulverizados com diferentes concentrações de $\mathrm{GA}_{3}$.

O ganho de massa é comprovado pela medição do peso dos frutos (Figuras 2, 3 e 4). De acordo com a Portaria 553 do Ministério da Agricultura, Pecuária e Abastecimento, o tomate oblongo é classificado em três classes, conforme o maior diâmetro transversal, sendo considerado grande, o fruto maior que $60 \mathrm{~mm}$. O transversal apresentado foi acima de $70 \mathrm{~mm}$, comprovando o bom tamanho desta cultivar, o que foi ressaltado com o uso do fitorregulador. Segundo Castro e Inoue (1977), o GA 3 produz mais frutos triloculares, o que pode explicar o aumento das dimensões do fruto.

Entretanto, ao aplicarem $\mathrm{GA}_{3}$ na planta inteira, Martins e Castro (1997) não observaram diferenças significativas no comprimento e diâmetro médio dos frutos, mas citam uma tendência à redução no tamanho dos mesmos. Além disso, há relatos na literatura de que uma pulverização de auxinas misturadas com giberelinas apresentam um efeito sinérgico no crescimento de tomateiros (Luckwill, 1959; Starck e Ciesla, 1989). Por outro lado, Castro e Malavolta (1976) relatam que o $\mathrm{GA}_{3}$ reduziu a massa média dos frutos de tomate, enquanto Kim e Jeong (1996) observaram o aparecimento de frutos anômalos, e a nível anatômico por uma contração dos lóculos produzida pela ausência de placentas e sementes (Castilho et al., 2005).

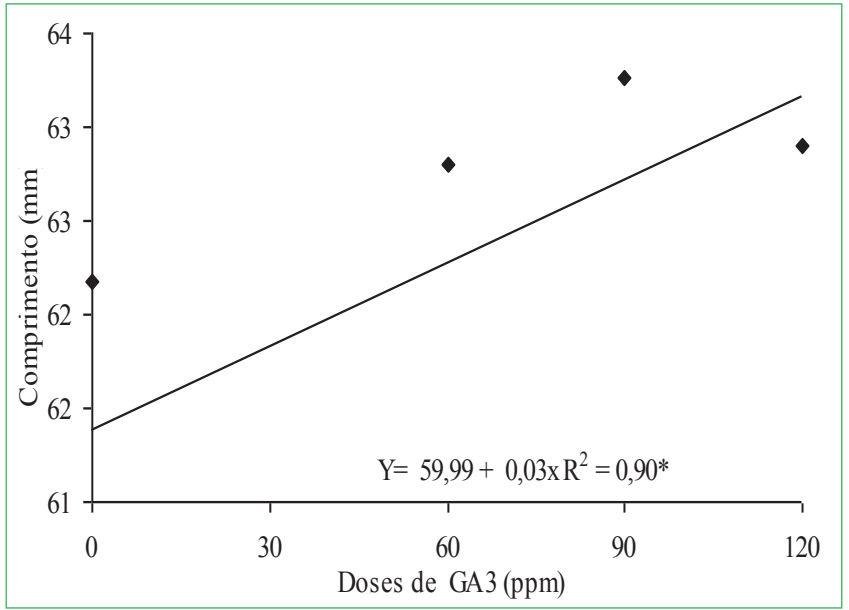

FIGURA 2: Comprimento de frutos de tomate (Lycopersicon esculentum Mill., Solanaceae) cv. Fanny pulverizados com diferentes concentrações de $\mathrm{GA}_{3}$.

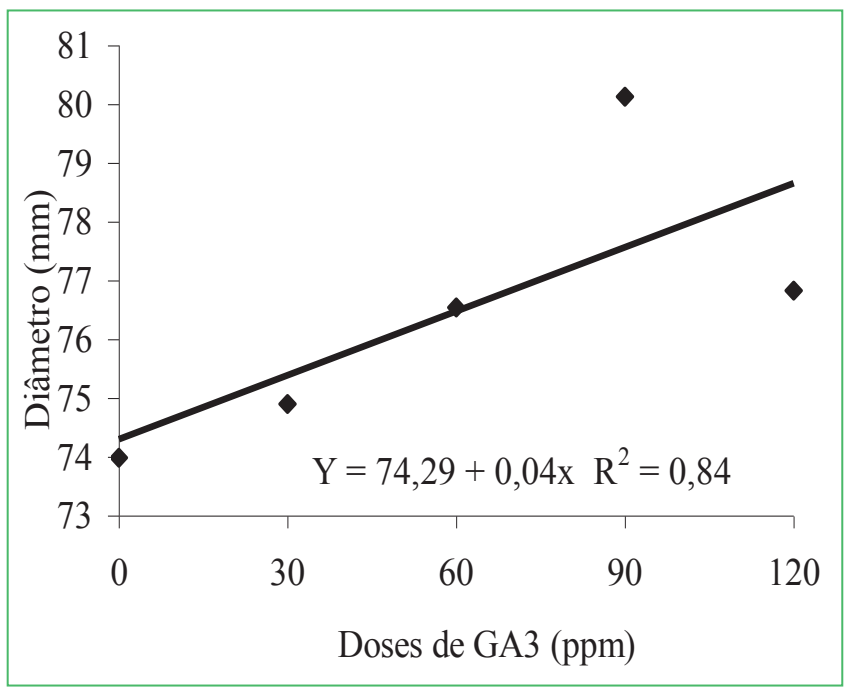

FIGURA 3: Diâmetro dos frutos de tomate (Lycopersicon esculentum Mill., Solanaceae) cv. Fanny pulverizados com diferentes concentrações de $\mathrm{GA}_{3}$.

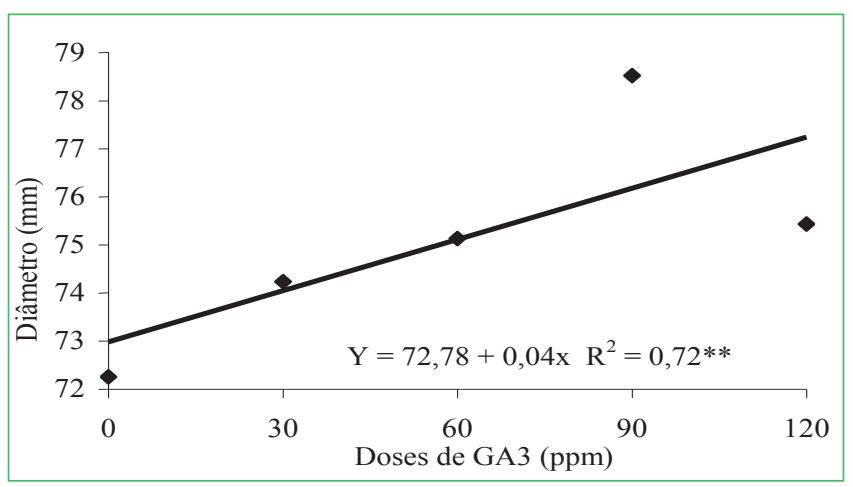

FIGURA 4: Diâmetro Transversal dos frutos de tomate (Lycopersicon esculentum Mill., Solanaceae) cv. Fanny pulverizados com diferentes concentrações de $\mathrm{GA}_{3}$. 
Gillaspy et al. (1993) relatam que o desenvolvimento do ovário depende do reconhecimento de sinais hormonais específicos, os quais são gerados antes e depois da fertilização e induzem genes responsáveis pela diferenciação dos tecidos que formam frutos e sementes.

A partir dos resultados encontrados nesse trabalho foi possível concluir que a aplicação de $120 \mathrm{ppm}$ de $\mathrm{GA}_{3}$ proporcionou máxima massa fresca e dimensões de frutos de tomate cv. Fanny.

\section{Referências}

Aguero, M. S.; Granell, A.; Carbonell, J. 1996. Expression of thiol proteases decreases in tomato ovaries after fruit set induced by pollination or giberellic acid. Plant Physiology, 98: 235-240.

Bunger-Kibler, S.; Bangerth, F. 1982. Relationship between cell number, cell size and fruit size of seeded fruit of tomato (Lycopersicon esculentum Mill.), and those inducedparthenocarpically by application of plant growth regulators. Plant Growth Regulators, 1: $143-145$.

Cançado Junior, F. L., Camargo Filho, W. P.; Estanislau, M. L. L.; Paiva, B. M.; Mazzei, A. R.; Alves, H. S. 2003. Aspectos econômicos da produção e comercialização do tomate para mesa. Informe Agropecuário, 24 (219): 7-18.

Castillo, O. E.; Barral, G.; Rodríguez, G. E.; Miguelisse, N. E.; Agüero, M. S. 2005. Establecimiento y desarrollo en el cultivo forzado de tomate. Efecto de fitorreguladores. Revista de la Facultad de Ciencias Agrarias UnCuyo, 37 (2): 83-91.

Castro, P. R. C.; Inoue, S. 1977. Indução de ovários trilocular em tomateiro (Lycopersicum esculentum Mill.) pelo ácido succínico2,2-dimetil-hidrazida. Ciência e Cultura, 29 (1): 65-67.
Castro, P. R. C.; Malavolta, E. 1976. Efeitos de reguladores de crescimento na frutificação do tomateiro cv. Miguel Pereira. Anais da Escola Superior de Agricultura "Luiz de Queiroz", Piracicaba, Brasil, p.201-210.

Fontes, P. C. R.; Silva, D. J. H. 2002. Produção de tomate de mesa. $1^{a}$ ed. Aprenda Fácil, Viçosa, Brasil, 193pp.

Gillaspy, G.; Bem-David, H.; Gruissen, W. 1993. Fruits: a developmental perspective. Plant Cell, 5: 1439-1451.

Kerbauy, G. B. 2004. Fisiologia vegetal. Guanabara Koogan, Rio de Janeiro, Brasil, 452pp.

Kim, I. S.; Jeong, C. S. 1996. Effect of growth regulators on puffyfruit, content of sugar and organic acid in tomato (Lycopersicum esculentum Mill.). Journal of the Korean Society for Horticultural Science, 37 (2): 187-192.

Lima, A. N.; Batista, J. de L.; Costa, N. P. 2005. Efeito de variedades de tomateiro no controle da mosca-branca (Bemisia tabaci L.). Caatinga, 18 (2): 92-97.

Luckwill, L. C. 1959. Fruit growth in relation to internal and external chemical stimuli. In: Rudnick, D. (Ed.). Cell, organism and milieu. Ronald Press, New York, USA, p.223-251.

Man, S.; Fontes, P. C. R.; Silva, D. J. da. 2003. Práticas culturais adequadas ao tomateiro. Informe Agropecuário, 24: 19-25.

Martins, M. B. G.; Castro, P. R. de C. 1997. Biorreguladores na morfologia e na produtividade de frutos de tomateiro cv. Ângela Gigante. Bragantia, 56: 237-248.

Sawhney, V. K. 1984. Gibberellins and fruit formation in tomato: a review. Science Horticultural, 22: 1-8.

Starck, Z.; Ciesla, E. 1989. Possible role of growth regulators in adaptation to heat stress affecting partitioning of photosynthates in tomato plants. Acta Societatis Botanicorum Poloniae, 58: 71-84.

Stover, E. W.; Stoffella, P. J.; Garrison, S. A.; Leskovar, D. I.; Sanders, D. C.; Vavrina, C. S. 2000. Bloom and postbloom applications of NAD/NAA mixture have minimal effects on yield and fruit size of field-grown tomatoes and peppers. HortScience, 35: $1263-1264$ 